\title{
Heart Weight and Heart Weight/Body Weight Coefficient in Malnourished Adults
}

\author{
Daniel Ferreira da Cunha, Selma Freire de Carvalho da Cunha, Marlene Antônia dos Reis, \\ Vicente de Paula Antunes Teixeira
}

Uberaba, MG - Brazil

\begin{abstract}
Objective - To compare the heart weight and the heart weight/body weight coefficient of adults with and without chronic malnutrition.
\end{abstract}

Methods - In an initial case series of 210 autopsies performed in adults, we recorded body and heart weights and calculated the heart weight/body weight coefficients (HW/BWx 100). The exclusion criteria were as follows: positive serology for Chagas' disease, edema, obesity, heart diseases, hepatopathies, nephropathies, and systemic arterial hypertension. Malnutrition was characterized as a body mass index $<18.5 \mathrm{~kg} / \mathrm{m}^{2}$. Differences with $p<0.05$ wereconsidered significant.

Results - Individuals in the malnourished $(n=15)$ and control $(n=21)$ groups were statistically different,

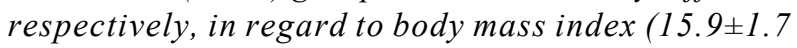
versus $\left.21.3 \pm 2.5 \mathrm{~kg} / \mathrm{m}^{2}\right)$, heart weight $(267.3 \pm 59.8$ versus $329.1 \pm 50.4 \mathrm{~g})$, and the $H W / B W$ coefficient $(0.64 \pm 0.12$ versus $0.57 \pm 0.09 \%$ ). A positive and significant correlation was observed between heart weight and body mass index $(r=0.52)$, and between heart weight and body weight $(r=0.65)$.

Conclusion - Malnourished individuals have lighter hearts and areater $H W / B W$ coefficient than non-malnourished individuals do. Thesefindings indicate a possible preservation of the myocardium in relation to the intensity of weight loss associated with the probable relative increase in cardiac connective tissue and heart blood vessels.

Key words: heart, cardiac hypotrophy, nutrition, proteincalorie malnutrition

Faculdade de Medicina do Triângulo Mineiro, Uberaba

Mailing address: Daniel Ferreira da Cunha - Nutrologia - Faculdade de Medicina do Triângulo Mineiro - Av. Getúlio Guaritá, 130 - 38025-180 - Uberaba, MG, Brazil - E-mail: dfcnutro@mednet.com.br

English version by Stela Maris C. e Gandour
Chronic malnutrition results from the inadequate intake of nutrients, with the predominance of catabolic processes over the anabolic ones, and the progressive wasting of fat and muscle protein body reserves. In adult individuals, chronic protein-calorie malnutrition manifests as progressive weight loss with hypofunction and hypotrophy of organs, such as the spleen, intestines, and kidneys ${ }^{1}$. Experiments with animals ${ }^{2}$ and autopsies of malnourished children show that the heart undergoes hy potrophy proportional to the degree of weight loss $\mathrm{s}^{3,4}$. Even though studies on heart morphometry and function of malnourished adults are rare ${ }^{5}$, experiments with animals suggest that the myocardium undergoes a milder wasting than striated skeletal muscles do, possibly due to the relative increase in vascularization and oxygenation of the myocardiocytes ${ }^{6}$. However, patients quite frequently develop tachycardia, hydric retention, and cardiac decompensation during nutritional therapy, and this phenomenon has been attributed to myocardial dysfunction associated with cardiac hypotrophy secondary to malnutrition ${ }^{7}$.

The heart weight/body weight (HW/BW) coefficient, whose normal value is around $0.5 \pm 0.02$, has been used for characterizing myocardial hypertrophy ${ }^{8}$ and could be used for assessing myocardial hypotrophy. A study carried out by our group ${ }^{8}$, even though with other objectives, showed that individuals dying with cachexia had a HW/BW coefficient greater than normal. However, the relations between the HW/BW coefficient and other parameters of nutritional assessment, such as body weight, height, and body mass index, have not yet been established.

Our hypothesis was that, due to the relative preservation of cardiac weight in relation to body mass index, malnourished adults would have a greater HW/BW coefficient than that of non-malnourished control individuals. The objective of our study was to compare heart weight and the HW/BW coefficient of adults with and without chronic malnutrition. 


\section{Methods}

The study was carried out in the departments of nutrition and general pathology of the Medical School of Triângulo Mineiro (FMTM), in the city of Uberaba, State of Minas Gerais, after approval by the Committee on Medical Ethics of the university-affiliated hospital. In the first phase, of a total of 315 autopsies performed at the university-affiliated hospital from December 1986 to January 1998, we selected 210 reports of complete autopsies performed in adults older than 21 years.

The major diagnoses established on autopsy and the general data of the patients, such as sex, color, age, height, body and cardiac weights, were stored in an electronic database. Later, patients with chagasic, hypertensive, ischemic, rheumatic, and pulmonary heart disease were excluded from the study. Due to the influence of edema on body weight, patients with anasarca or localized noninflammatory edema were excluded, as were patients with signs of chronic hepatopathy (viral hepatitis, alcoholic hepatitis, or cirrhosis), glomerulopathy, and with obesity defined as a body mass index greater than $27 \mathrm{~kg} / \mathrm{m}^{2}$. Positive serological reactions for Chagas' disease and the presence of intracardiac thrombosis or pericarditis were also considered exclusion criteria, as was the presence of morphological renal signs suggestive of chronic renal insufficiency, which is a condition frequently associated with cardiomegaly ${ }^{9}$.

The nutritional status was characterized by body mass index, which was calculated by dividing body weight in kilos by height in square meters $\left(\mathrm{kg} / \mathrm{m}^{2}\right)$; individuals with body mass index $<18.5 \mathrm{~kg} / \mathrm{m}^{2}$ were considered malnourished ${ }^{10}$. The HW/BW coefficient [heart weight (g)/body weight (g) $x$ 100] was calculated in all cases ${ }^{8}$. After verifying the statistical normality of the numerical continuous data obtained, the malnourished and control groups were compared using the Student $t$ test. The chi-square test and Fisher exact test were used for comparing proportions. Pearson correlation coefficient was used to assess the correlations between body weight and heart weight, and between body mass index and heart weight. Differences with $p<0.05$ were considered significant.

\section{Results}

We analyzed 36 patients, 15 of whom had protein-calorie malnutrition and 21 were control individuals. Malnourished patients and control patients did not statistically differ in regard to, respectively, age $(42.3 \pm 18.3$ versus $44.7 \pm 21.8$ years), sex proportion (male:female $=11: 4$ versus $18: 5$ ), and color (white:nonwhite $=10: 5$ versus 16:5) . Likewise, the percentages of the most common diagnoses on autopsy for malnourished and control patients were similar and as follows, respectively: bronchopneumonia (40 versus 38.1 ), gastritis (40 versus 28.6), acquired immunodeficiency syndrome (26.7 versus 19.9), malignant neoplasias (13.3 versus 19), chronic pancreatitis (13.3 versus 33.3), and sepsis
(13.3 versus 19). No gross or microscopic cardiac alterations compatible with the diagnoses of degeneration, necrosis, inflammatory infiltrate, or presence of parasites were observed.

The patients in the malnourished and control groups had similar heights, $1.62 \pm 0.12$ meters versus $1.65 \pm 0.08$ meters, respectively. Malnourished patients, however, had lower body weight and body mass index than those of the control group $(p<0.05)$ (tab. I). Heart weight was lower in the malnourished patients $(267.3 \pm 59.8 \mathrm{~g})$ as compared with those in the control patients $(329.1 \pm 50.4 \mathrm{~g})$, but the HW/BW relation was greater in the malnourished group $(0.64 \pm 0.12 \%)$ than in the control group $(0.57 \pm 0.09 \%)$. The correlations between body weight and heart weight (fig. 1) and between body mass index and heart weight (fig. 2) were positive and significant $(\mathrm{p}<0.05)$.

\section{Discussion}

In our study, we observed that the heart is proportionally heavier in malnourished adults than in non-malnourished control individuals. This phenomenon may be interpreted as a manifestation of relative heart preservation in regard to the intensity of body weight loss. This interpretation is in accordance with the report of greater HW/BW coefficients in thinner individuals as compared with those in individuals with a greater body weight ${ }^{11}$ and also with the observance of $\mathrm{HW} / \mathrm{BW}$ coefficients of $0.60 \pm 0.13 \%$ in individuals dying due to diseases accompanied by cachexia ${ }^{8}$.

The exclusion of obese individuals, individuals with heart diseases and with systemic diseases, such as syste-

\begin{tabular}{|lcc|}
\hline \multicolumn{3}{|c|}{ Table I - Age, anthropometric parameters, and cardiac weight in } \\
malnourished and control adults. \\
\hline Carameters & Controls & Malnourished \\
& $(\mathrm{n}=21)$ & $(\mathrm{n}=15)$ \\
\hline Age (years) & $44.7 \pm 21.8$ & $42.3 \pm 18.3$ \\
Body mass index $\left(\mathrm{kg} / \mathrm{m}^{2}\right)$ & $21.3 \pm 2.46$ & $15.9 \pm 1.69 *$ \\
Body weight $(\mathrm{kg})$ & $58.2 \pm 7.2$ & $41.9 \pm 6.7 *$ \\
Cardiac weight $(\mathrm{g})$ & $329.1 \pm 50.4$ & $267.3 \pm 59.8 *$ \\
Cardiac weight/body weight $(\%)$ & $0.57 \pm 0.09$ & $0.64 \pm 0.12 *$ \\
\hline * $\mathrm{p}<0.01$ & & \\
\hline
\end{tabular}

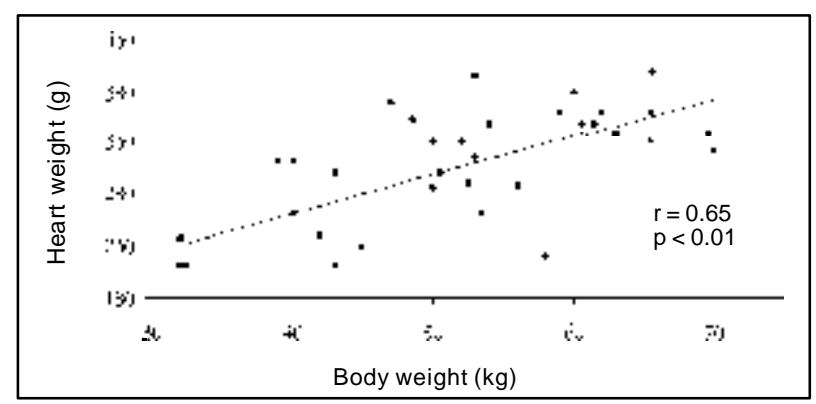

Fig. 1 - Correlation between body weight $(\mathrm{kg})$ and cardiac weight $(\mathrm{g})$ in malnourished and control adults. 


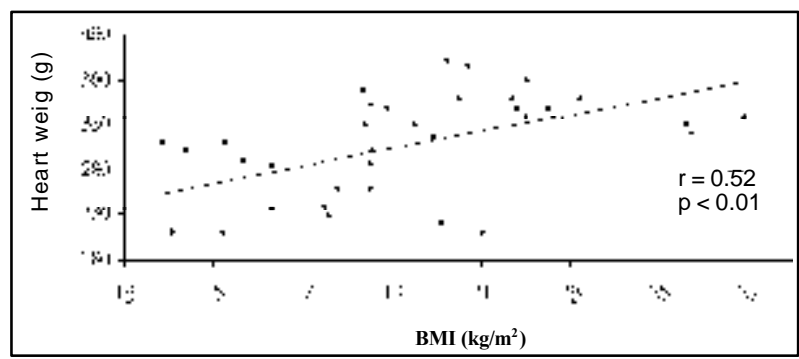

Fig. 2 - Correlation between body mass index (BMI) and heart weight in malnourished and control adults.

mic arterial hypertension or chronic renal insufficiency, reduced the possibility of the concomitance of conditions causing myocardial hypertrophy or cardiac dilation ${ }^{12}$. Likewise, the exclusion of patients with edema or cavitary effusions also increased the reliability of the anthropometry in assessing nutritional status ${ }^{10}$.

According to the criteria used in this study, which did not include individuals with protein malnutrition of the kwashiorkor type ${ }^{1}$, we can state that a predominance of individuals with malnutrition of the marasmus type occurred. This malnutrition results from prolonged negative calorie balance, characterized by a marked wasting of body fat reserves and a relative preservation of muscle mass. Even though the type of malnutrition is rarely detailed in studies performed with adults ${ }^{1}$, the heart has been reported to be relatively spared in prolonged malnutrition ${ }^{1,3,4}$, which sup- ports the finding of a greater heart weight/body weight coefficient observed in the present study.

However, we also observed a positive and significant correlation between body weight and heart weight $(r=0.65)$, and also between heart weight and body mass index $(\mathrm{r}=0.52)$, which indicates that the thinner the individual, the lower his heart weight is. Likewise, according to morphometric studies on myocardiocytes ${ }^{5}$, individuals with advanced malnutrition have greater degrees of heart hypotrophy ${ }^{13}$. This fact may have clinical repercussions, such as a prolonged QTc interval on the electrocardiogram ${ }^{14}$, alower cardiac output ${ }^{2}$, and a higher risk of developing the refeeding syndrome, a condition in which cardiac decompensation would result from myocardial dysfunction associated with cardiac hypotrophy secondary to malnutrition ${ }^{7}$. These data indicate that if myocardium undergoes hypotrophy, the same seems not to happen to the connective tissue in the heart ${ }^{3,5}$, a fact supported by the greater tortuosity of the coronary vessels and the disproportion between the size of the hypotrophic heart and the great vessels, which are not affected by malnutrition.

In conclusion, even though a relative preservation of cardiac weight in adults with marasmus has been reported, the results of our study also show cardiac hypotrophy associated with severe chronic malnutrition. Further studies may clarify whether at least part of the maintenance of the cardiac weight results from the relative increase in the connective tissue, which would be more preserved than the muscular one during prolonged starvation.

\section{References}

1. McMahon MM, Bistrian BR. The physiology of nutritional assessment and therapy in protein-calorie malnutrition. Dis Mon 1990;36: 373-417.

2. Alden PB, Madoff RD, Stahl TJ, Lakatua DJ, Ring WS, Cerra FB. Left ventricular function in malnutrition. Am J Physiol 1987; 253: H380-7.

3. Webb JG, Kiess MC, Chan-Yan CC. Malnutrition and the heart. Can Med Assoc J 1986; 135: 753-8

4. Freeman LM, Roubenoff R. The nutrition implications of cardiac cachexia. Nutr Rev 1994; 52:340-7.

5. Cunha DF, Pedrini CH, Sousa JC, et al. Estudo morfométrico do miocárdio em adultos com subnutrição protéico-energética. Arq Bras Cardiol 1998;71: 677-80.

6. Vandewoude MF. Morphometric changes in microvasculature in rat myocardium during malnutrition. J Parenter Enteral Nutr 1995; 19: 376-80.

7. Brooks MJ, Melnik GM. The refeeding syndrome: an approach to understanding its complications and preventing its occurence. Pharmacotherapy 1995; 15:713-26.

8. Almeida HO, Teixeira VPA, Araújo WF. Comportamento do peso do coraçãoe docorpo em chagásicos crônicos come sem "megas". Rev Soc Bras Med Trop 1979; 13: 85-9.
9. Suzuki H, Schaefer L, Ling H, et al. Prevention of cardiac hypertrophy in experimental chronic renal failure by long-term ACE inhibitor administration: potential role of lysosomal proteinases. Am J Nephrol 1995; 15: 129-36.

10. James WP, Ferro-Luzzi A, Waterlow JC. Definition of chronic energy deficiency in adults: report of a working party of the International Dietary Energy Consultative Group. Eur J Clin Nutr 1988; 42: 969-81.

11. Hanzlick R, Rydzewski D. Heart weights of white men 20 to 39 years of age: an analysis of 218 autopsy cases. Am J Forensic Med Pathol 1990; 11:202-4.

12. Warnes CA, Roberts WC. The heart in massive (more than 300 pounds or $136 \mathrm{ki}$ lograms) obesity: analysis of 12 patients studied at necropsy. Am J Cardiol 1984; 54: 1087-91.

13. Vandewoude MF, Cortvrindt RG, Goovaerts MF, Van Paesschen MA, Buyssens N. Malnutrition and the heart: a microscopic analysis. Infusionstherapie 1988; 15:217-20.

14. Cunha DF, Cunha SFC, Ferreira TPS, et al. Prolonged QTc intervals on the electrocardiograms of hospitalized malnourished adults. Nutrition 2001; 17:370-2. 